\title{
Variation of the cochlear anatomy and cochlea duct length: analysis with a new tablet-based software
}

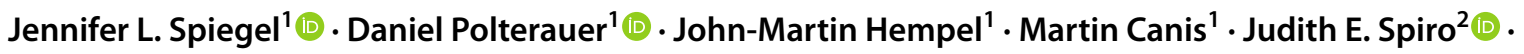 \\ Joachim Müller ${ }^{1}$
}

Received: 17 January 2021 / Accepted: 17 May 2021 / Published online: 29 May 2021

(c) The Author(s) 2021

\begin{abstract}
Purpose In cochlear implantation, thorough preoperative planning together with measurement of the cochlear duct length (CDL) assists in choosing the correct electrode length. For measuring the CDL, different techniques have been introduced in the past century along with the then available technology. A tablet-based software offers an easy and intuitive way to visualize and analyze the anatomy of the temporal bone, its proportions and measure the CDL. Therefore, we investigated the calculation technique of the CDL via a tablet-based software on our own cohort retrospectively.

Methods One hundred and eight preoperative computed tomography scans of the temporal bone (slice thickness $<0.7 \mathrm{~mm}$ ) of already implanted FLEX28 ${ }^{\mathrm{TM}}$ and FLEXSOFT ${ }^{\mathrm{TM}}$ patients were found eligible for analysis with the OTOPLAN software. Measurements were performed by two trained investigators independently. CDL, angular insertion depth (AID), and cochlear coverage were calculated and compared between groups of electrode types, sex, sides, and age.

Results Mean CDL was $36.2 \pm 1.8 \mathrm{~mm}$ with significant differences between sex (female: $35.8 \pm 0.3 \mathrm{~mm}$; male: $36.5 \pm 0.2 \mathrm{~mm}$; $p=0.037$ ), but none concerning side or age. Differences in mean AID (FLEX28: 525.4 $\pm 46.4^{\circ}$; FLEXSOFT: $615.4 \pm 47.6^{\circ}$ ), and cochlear coverage (FLEX28: 63.9 $\pm 5.6 \%$; FLEXSOFT: $75.8 \pm 4.3 \%)$ were significant $(p<0.001)$.

Conclusion A broad range of CDL was observed with significant larger values in male, but no significant differences concerning side or age. Almost every cochlea was measured longer than $31.0 \mathrm{~mm}$. Preoperative assessment aids in prevention of complications (incomplete insertion, kinking, tipfoldover), attempt of atraumatic insertion, and addressing individual necessities (hearing preservation, cochlear malformation). The preferred AID of $720^{\circ}$ (two turns of the cochlea) was never reached, opening the discussion for the requirement of longer CI-electrodes versus a debatable audiological benefit for the patient in his/her everyday life.
\end{abstract}

Keywords OTOPLAN $\cdot$ Morphology of the cochlea $\cdot \mathrm{CDL} \cdot$ Cochlear duct length $\cdot$ Digitalization $\cdot$ Anatomy of the cochlea

JudithE. Spiro and Joachim Müller have contributed equally.

Jennifer L. Spiegel

jennifer.spiegel@med.uni-muenchen.de

Daniel Polterauer

daniel.polterauer@med.uni-muenchen.de

John-Martin Hempel

john-martin.hempel@med.uni-muenchen.de

Martin Canis

martin.canis@med.uni-muenchen.de

Judith E. Spiro

judith.spiro@med.uni-muenchen.de
Joachim Müller

joachim.mueller@med.uni-muenchen.de

1 Department of Otorhinolaryngology, LMU Klinikum, Ludwig-Maximilians-Universität München, Marchioninistr. 15, 81377 Munich, Germany

2 Department of Radiology, University Hospital, LMU Munich, Munich, Germany 


\section{Introduction}

Detailed knowledge of the morphology of the cochlea has always been in the center of interest of otologists in particular prior to performing surgery. Attention has always been paid to surgical anatomy, either due to the presence of inner ear malformations [1], or the size of the cochlea and cochlear duct length (CDL) [2-4]. In addition, surgical techniques with the aim of hearing preservation [5], or the prevention of postoperative vertigo in terms of treating patients with an large vestibular aqueduct or prevention of accidental penetration of the scala vestibuli [6]. Thus, to account those issues, a variety of cochlear implant (CI) electrodes have been developed, which are offered to surgeons with different lengths, and position within the scala tympani, resulting in electrodes that are placed alongside to the lateral wall (https://s3.medel.com/pdf/ 21617.pdf. Accessed 8 April 2020) [7], within the middle of the scala (https://www.advancedbionics.com/conte nt/advancedbionics/com/en/home/products/hi-focus-elect rode-family.html. Accessed 8 April 2020) [8, 9], or against or close to the modiolus (http://www.cochlear.com/wps/ $\mathrm{wcm} /$ connect/us/home/treatment-options-for-hearing-loss/ cochlear-implants. Accessed 8 April 2020) [10]. Depending on the indication, the surgeon selects the appropriate electrode for each patient individually. Nowadays, thorough preoperative planning with measurement of the CDL assists in choosing the correct electrode length.

For measuring the CDL, different techniques have been introduced in the past century along with the then available technology [11]. In the mid to late nineteenth century, several researchers throughout Europe, like Retzius, Hardy, or Bredberg, used the direct method to measure the length of the cochlea on histological sections by a micrometer [3]. Until the late 1980s only two methods, direct and indirect technique, were used to measure the CDL, with the indirect method exhibiting a possible underestimation of the CDL $[12,13]$. The direct technique measured the CDL directly with histologic slices, and the indirect reconstructed a two-dimensional model via a stack of histologic slices. Along with the emergence of new available technology, a computer-generated 3D model was introduced using histologic sections by Takagi and Sando [14]. In 1998, computed tomography (CT) has evolved as a useful tool to detect inner ear malformations and for preoperative CI planning. The cochlear spiral length was calculated by different dimensions of the cochlea (apical diameter and spiral constant) via an Archimedean spiral equation [15]. In 2012, after further milestone improvements by Escudé and collaborators [16], Alexiades et al. generated a formula calculating the CDL developing a more straightforward technique. Based on Escudé's spiral equation, a linear equation was developed [17], which is also used for measurement of the average electrode radius. Using the method of Alexiades et al., the tablet-based software OTOPLAN (https://www.cascination.com/products/otopl an. Accessed 8 April 2020) [18], developed by CAScination AG (Bern, Switzerland), offers an easy and intuitive way to analyze the anatomy of the temporal bone, its proportions, and to measure the CDL [19]. Therefore, we used this straightforward tablet-based software to retrospectively measure and analyze the CDL on our own cohort. Objectives of the study were to evaluate the range of CDL, find differences in different patient groups (sex, age, type of electrode), and to assess the angular insertion depth (AID) for the cochlear coverage.

\section{Materials and methods}

\section{Ethical standards and patients}

We performed a retrospective analysis of preoperative CT images of 357 consecutive patients/378 consecutive ears that had undergone cochlear implantation with either a FLEX $28^{\mathrm{TM}}$ or FLEXSOFT ${ }^{\mathrm{TM}}$ electrode by MED-EL (MEDEL GmbH, Innsbruck, Austria). Implantation of all patients was performed prior to availability of the tablet-based software OTOPLAN. All patients were treated between 2011 and 2018 at one academic tertiary referral center. Of those 378 CT images (radiologic Digital Imaging and Communications in Medicine $\left(\mathrm{DICOM}^{\circledR}\right)$, with a range of slice thickness of 0.3 to $2.0 \mathrm{~mm}$, all scans were checked for eligibility of upload to the tablet. From our own experiences, a slice thickness of $\geq 0.7 \mathrm{~mm}$ lead to impreciseness of measurements. Exclusion criteria were: cochlear malformations, thickness of CT slices $\geq 0.7 \mathrm{~mm}$, data sets, which failed to be uploaded to the OTOPLAN software (see Fig. 1). A chart analysis of the included patients was performed after identifying candidates with the described patient's characteristics from the CI-patient registry. Implantation of CI was performed prior to availability of the tablet-based software. FLEX 28 electrodes were implanted in patients, in whom hearing preservation was aimed. In all patients a complete insertion was achieved. All patients received postoperative standard radiologic checkup via a Stenvers view head X-ray to rule out a kinking or tip fold over of the inserted electrode, and suggested an insertion of approximately 2 turns of the cochlea equal to $720^{\circ}$.

The study was approved by the Institutional Review Board and Ethics Committee of the Ludwig-MaximiliansUniversität München, Munich, Germany (Ethikkommission der LMU München), reference number 19-562. Procedures were followed in accordance with the ethical standards of the Helsinki Declaration [20]. 


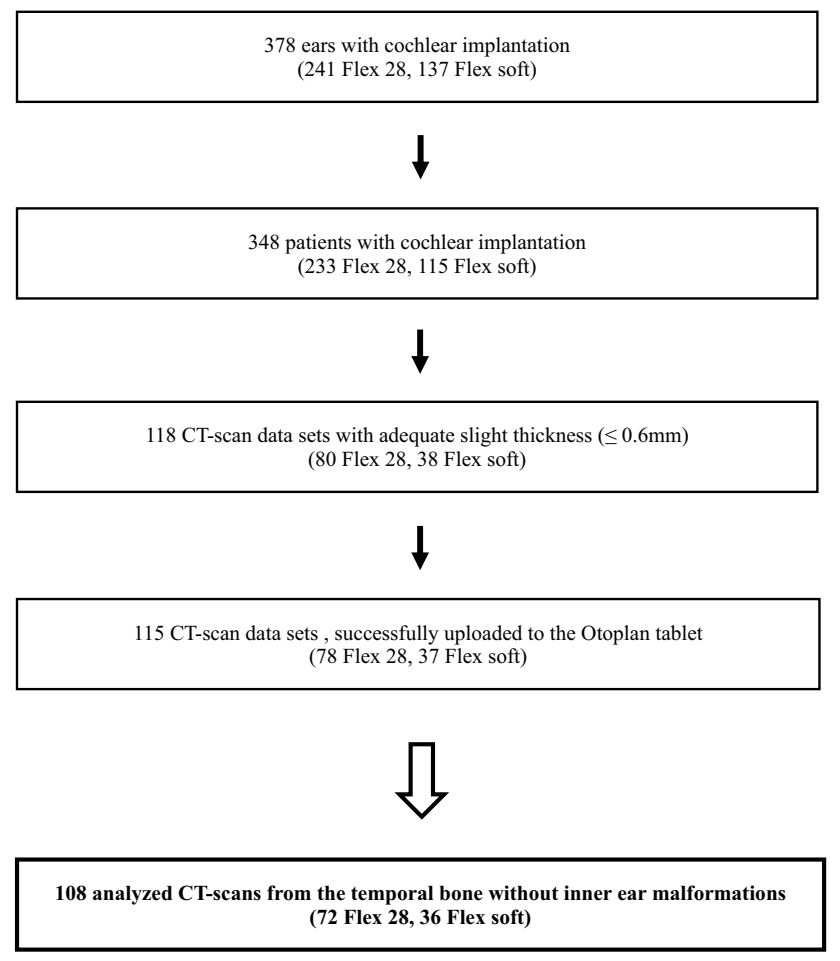

Fig. 1 Inclusion criteria. Flowchart of cases included in and excluded from the analysis. Exclusion criteria: inner ear malformations, slice thickness $\geq 0.7 \mathrm{~mm}$

\section{Software}

The software OTOPLAN was developed by CAScination AG (Bern, Switzerland). OTOPLAN is an easy to use tabletbased software, which provides functionalities and detailed information that exceeds the usual DICOM ${ }^{\circledR}$ viewer output. It features a plug and play data management, intuitive touch controls, fast and easy 3D visualization, measurement of crucial structures like the cochlea, electrode visualization, and bespoke matching as well as comprehensive patient reporting and post-op analysis. In cooperation with MED-EL it is used for preoperative planning prior to cochlear implantation. For our analysis the OTOPLAN version 2.0 (https:// www.cascination.com/products/otoplan. Accessed 8 April 2020) [18] was used (CE-certification number: G1 1710 $95657003)$.

\section{Data analysis}

The CT scans were preoperative images, which were analyzed retrospectively after cochlear implantation. All $\mathrm{DICOM}^{\circledR}$ data sets were checked for image quality and malformations of the temporal bone by a radiologist with 6 years of experience in otorhinolaryngologic imaging (J.E.S.). The remaining DICOM ${ }^{\circledR}$ data were independently analyzed by two blinded investigators using multiplanar reformation (MPR): an image plane parallel to the basal turn of the cochlea was reconstructed, where 'A value' (largest distance from the round window to the contralateral wall)
Fig. 2 Steps of OTOPLAN. A Multiplanar reformation of the right inner ear reconstructed along the basal cochlear turn. The center of the modiolus (yellow cross) and the round window (yellow empty circle) are visible. $\mathbf{B}$ A value is measured as the distance between the round window and the contralateral cochlear wall: solid green line connecting two green dots. C B value represents the cochlear width perpendicular to the A value measurement: solid blue line connecting two blue dots. D Height of the cochlear is measured on a plane orthogonal to the basal turn of the cochlea: solid red line connecting two red dots
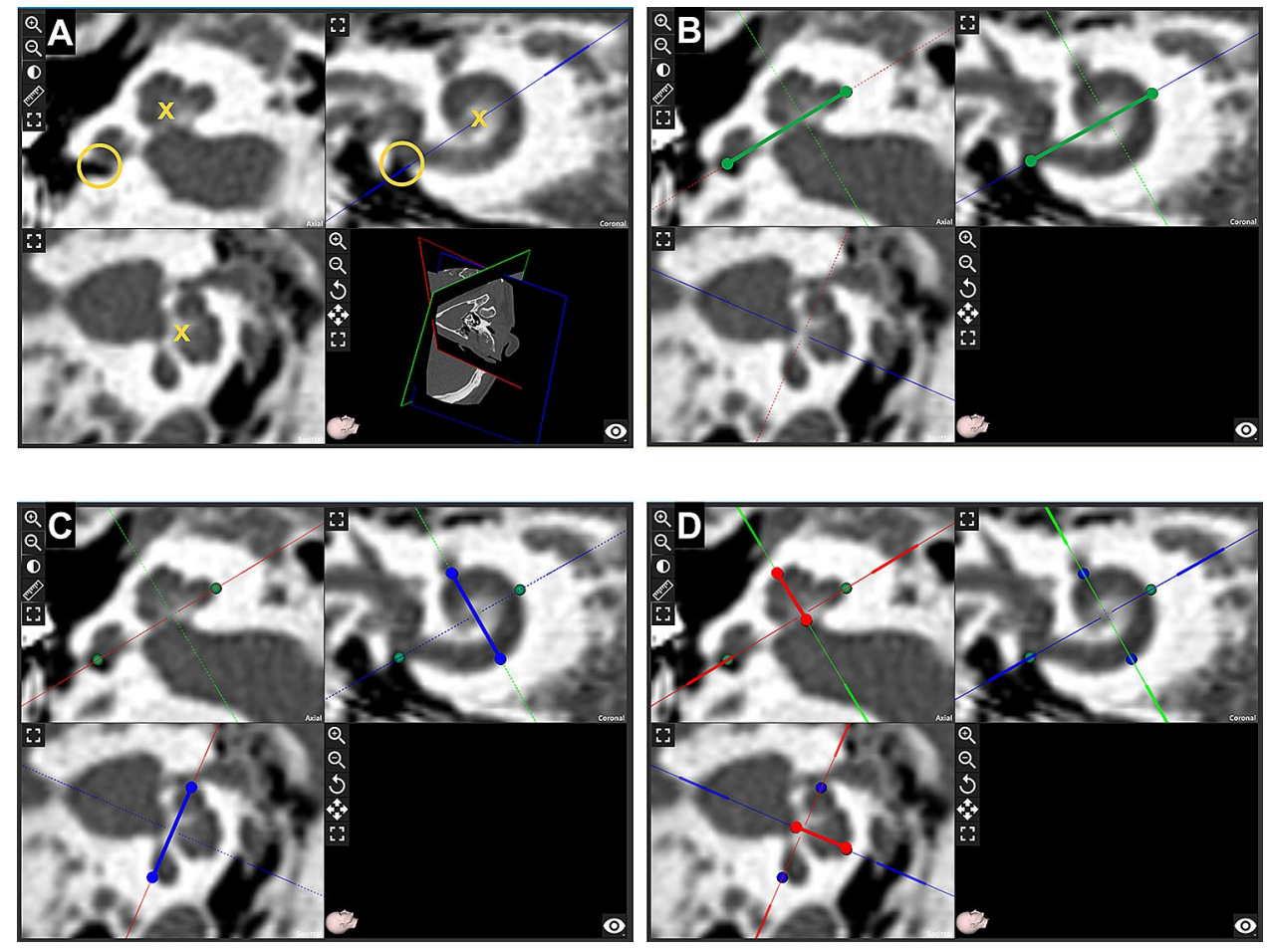
and 'B value' (distance between cochlear walls perpendicular to the A value line) were measured. The height of the cochlea was measured on an orthogonal plane. These details of the measurement process are illustrated in Fig. 2. With the determined values ("A", "B", height), the software OTOPLAN calculates the cochlear duct length according to the elliptic-circular approximation (ECA) method, which exhibits an improved accuracy compared to other techniques [21]. Thus, the cochlear coverage with AID, and cochlear place frequency on basis of the Greenwood function were calculated by the software according to a selected electrode [22]. Active stimulating length was defined by the deepest inserted point of the electrode. The FLEX28 $8^{\mathrm{TM}}$ has a total length of $28 \mathrm{~mm}$ with an active stimulating length of $23.1 \mathrm{~mm}$. Concerning the FLEXSOFT ${ }^{\mathrm{TM}}$, its whole length exhibits $31.0 \mathrm{~mm}$ and active stimulating length $26.4 \mathrm{~mm}$ [7]. All measurements were performed by two raters (J.E.S: radiologist; J.L.S.: otorhinolaryngologist), who were blinded to both the implanted electrodes and other rater's results.

\section{Statistical analysis}

The data analysis was generated using the Real Statistics Resource Pack software (Release 6.8) (Zaiontz C (2020) Real statistics using excel. www.real-statistics. com. Accessed 24 April 2020) [23] and Microsoft ${ }^{\circledR}$ Excel $^{\circledR}$ 16.0.12730.20144. Prior to comparison of the groups, the d'Agostino-Pearson test assessed no normal distribution. Levene's test was performed to investigate for equality of variances. Regarding comparing analysis, the Chi-square test and the Wilcoxon-Mann-Whitney $U$ test was applied. Differences were considered significant at $p$ values less than 0.05 .

All figures were created with Microsoft ${ }^{\circledR}$ Excel $^{\circledR}$ version 16.16.5 for iOS.

\section{Results}

After applying exclusion criteria, out of the 378 ears, a total of $108 \mathrm{CT}$ scans of the temporal bone (108 patients) were found eligible for the present study. Due to a high rate of scans with slice thickness of $0.7 \mathrm{~mm}$ or more, only a total of 72 FLEX $28^{\mathrm{TM}}$ implanted ears and 36 FLEXSOFT ${ }^{\mathrm{TM}}$ implanted ears were included into the investigation (Fig. 1). The cohort consisted of 55 female patients $(50.9 \%)$ and in $59.3 \%(n=64)$ of the whole cohort the right temporal bone was analyzed. The age ranged from 6.5 to 90.3 years with a mean of $56.3 \pm 19.9$ years.

The mean CDL of the whole investigated cohort was $36.2 \pm 1.8 \mathrm{~mm}$ (range: $30.4-40.2 \mathrm{~mm}$ ) with a variation over $30 \%$. No significant differences between the groups of different electrode types were observed (FLEX28 ${ }^{\mathrm{TM}}$ : $36.2 \pm 2.0 \mathrm{~mm}$; FLEXSOFT ${ }^{\mathrm{TM}}$ : $36.2 \pm 1.4 \mathrm{~mm} ; p=0.922$ ).
Table 1 Morphology of the cochleae

\begin{tabular}{lrrrrr}
\hline Morphology & FLEX 28 & FLEX & $p$ & $p$ value \\
& & & SOFT & \\
\hline CDL $(\mathrm{mm} \pm \mathrm{SD})$ & 36.2 & 2.0 & 36.2 & 1.4 & 0.922 \\
A value $(\mathrm{mm} \pm \mathrm{SD})$ & 9.4 & 0.4 & 9.5 & 0.4 & 0.559 \\
B value $(\mathrm{mm} \pm \mathrm{SD})$ & 7.0 & 0.4 & 7.0 & 0.3 & 0.465 \\
Height $(\mathrm{mm} \pm \mathrm{SD})$ & 4.2 & 0.3 & 4.2 & 0.3 & 0.793 \\
AID $( \pm \mathrm{SD})$ & 528.3 & 46.3 & 622.2 & 35.5 & $<0.001$ \\
Cochlear coverage $(\% \pm \mathrm{SD})$ & 63.9 & 5.6 & 75.8 & 4.3 & $<0.001$ \\
Length of C1 electrode & 402.0 & 103.6 & 211.5 & 56.3 & $<0.001$ \\
$\quad$ contact $(\mathrm{Hz} \pm \mathrm{SD})$ & & & & & \\
\hline
\end{tabular}

$A I D$ angular insertion depth; $C D L$ cochlear duct length; $n$ number; $S D$ standard deviation

The mean AID was $528.3 \pm 46.3^{\circ}$ for the FLEX28 $8^{\mathrm{TM}}$ and $622.2 \pm 35.5^{\circ}$ for the FLEXSOFT ${ }^{\mathrm{TM}}$ group $(p<0.001)$, resulting in a cochlear coverage of $63.9 \pm 5.6 \%$ for FLEX28 $8^{\mathrm{TM}}$ versus $75.8 \pm 4.3 \%$ for FLEXSOFT ${ }^{\mathrm{TM}}$, respectively. All data regarding the morphology are listed in Table 1. In none of the individuals an AID of $720^{\circ}$ was reached, which would equal to two turns of the cochlear. Figure 3A shows the relation of the AID to the CDL with regard to the type of electrode. When looking at a distribution function, half of the examined cochleae are in a range of $35.0-37.0 \mathrm{~mm}$ (Fig. 3B). In addition, only two cochleae $(1.8 \%)$ were measured shorter than $32.0 \mathrm{~mm}$, which means that in the rest of the cohort an electrode of $31.0 \mathrm{~mm}$ length would have fitted. Comparing the CDL between females $(35.8 \pm 0.3 \mathrm{~mm})$ and males $(36.5 \pm 0.2 \mathrm{~mm})$, a significant difference was observed ( $p=0.037$; Fig. 4A). Right $(36.1 \pm 0.2 \mathrm{~mm})$ and left $(36.3 \pm 0.3 \mathrm{~mm})$ ears showed no statistically different CDL ( $p=0.681$; Fig. 4B). Concerning a difference in CDL according to the age of the analyzed individuals, we found no difference or trend, as depicted in Fig. 4C. The analysis of the interrater reliability showed no significant differences between the two rater's measurements (CDL: $p=0.887$; A value: $p=0.454$; $\mathrm{B}$ value: $p=0.412$; height of the cochlea: $p=0.764$; AID: $p=0.519$; cochlear coverage: $p=0.627$; Fig. 5 A-F).

\section{Discussion}

Our analysis showed a significant difference of mean CDL with regard to sex, but not to age, side, or patients having received different types of CI-electrodes. Thus, a very broad and significant range in the CDL was observed with only two patients (1.8\%) exhibiting cochleae shorter than $31.0 \mathrm{~mm}$. In all patients the intended AID of approximately $720^{\circ}$, equal to two turns of the cochlea, was not reached, even if standard postoperative radiologic checkup via a Stenvers view head $\mathrm{X}$-ray would suggest. 


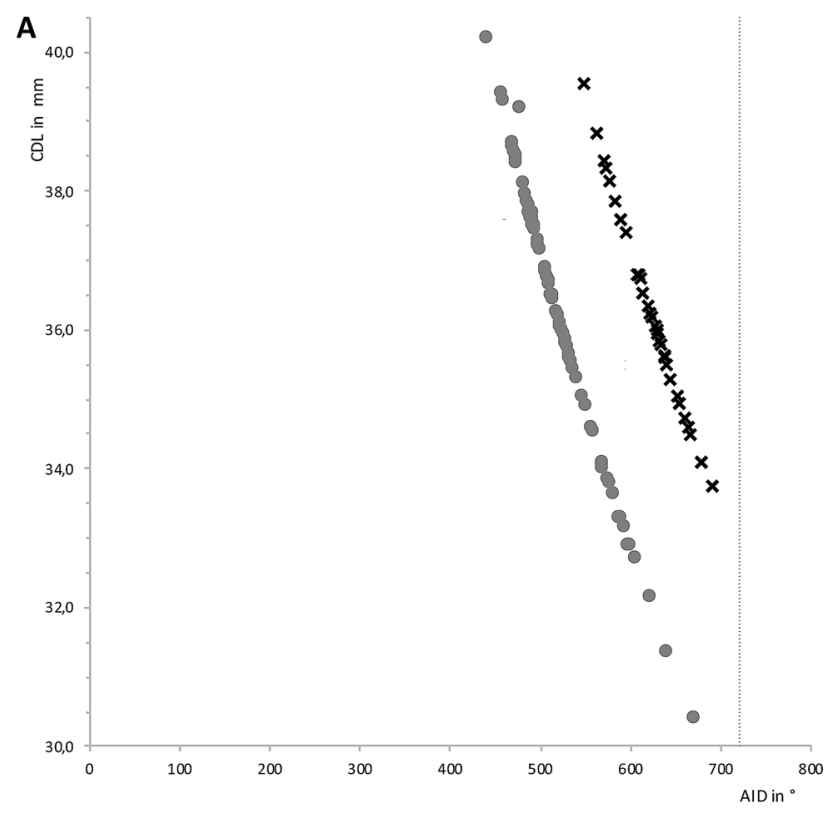

Fig. 3 Cochlear duct length versus angular insertion depth. A Scatter gram of the CDL (y-axis) and cochlear coverage (x-axis) between the two electrode types FLEX28 ${ }^{\mathrm{TM}}$ and FLEXSOFT ${ }^{\mathrm{TM}}$. The grey dots represent patients who received a FLEX $28^{\mathrm{TM}}$ electrode, the black crosses patients with FLEXSOFT ${ }^{\mathrm{TM}}$ electrodes. The dotted grey line

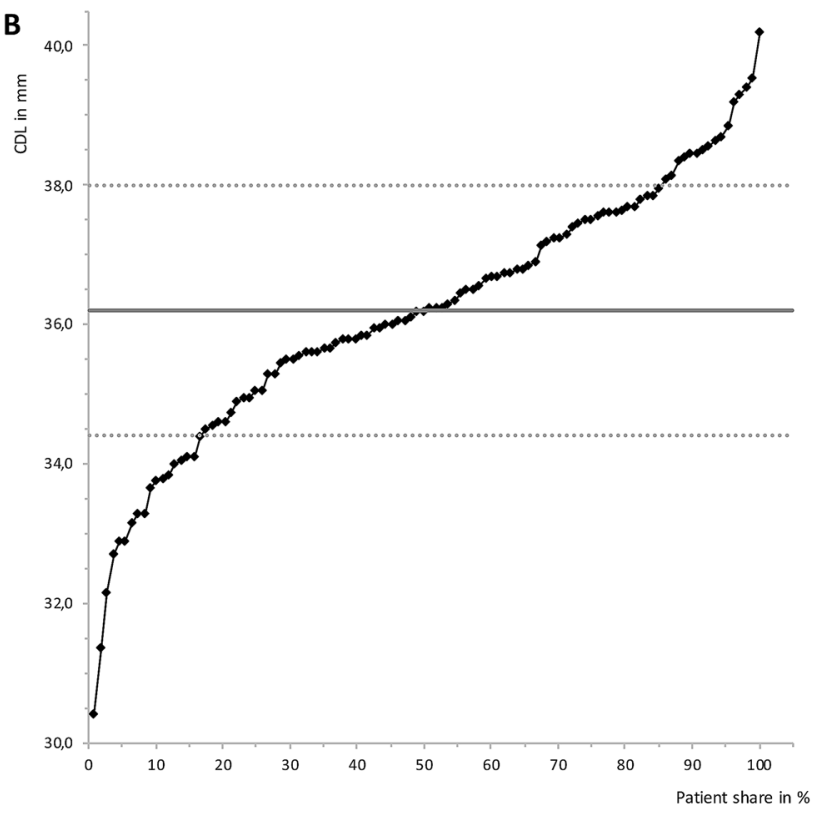

at the active stimulating length of $720^{\circ}$ indicates the length of 2 windings of the cochlear. B Distribution function of CDL (y-axis) and share of patients in percent (x-axis). The solid grey line indicates the mean of CDL, the dotted grey line the standard deviation. AID angular insertion depth; $C D L$ cochlear duct length
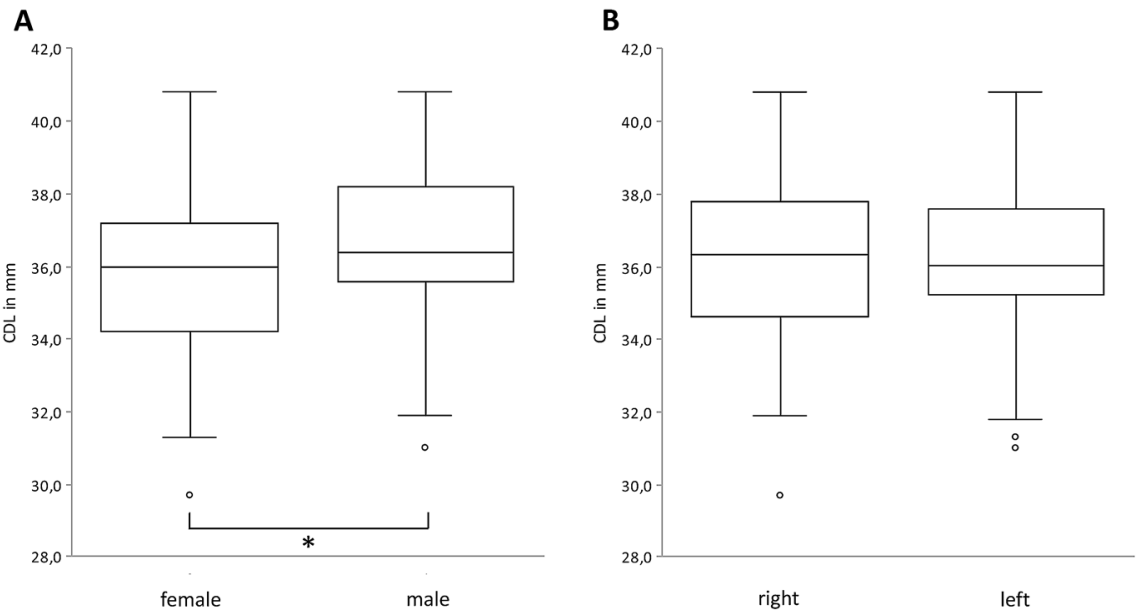

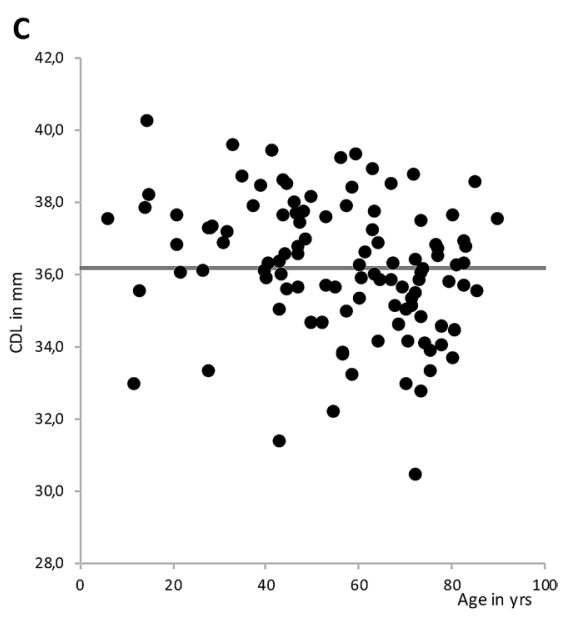

Fig. 4 Comparison of cochlear duct length-female versus male, right versus left and age distribution. A Comparison of CDL between female and male individuals. The asterisk marks statistically significant differences, the empty circles indicate outliners. B Comparison of cochlear duct length between right and left. The empty circles indi- cate outliners. C Age distribution in years of all analyzed individuals versus CDL. The black dots indicate each investigated individual, the grey solid line at $36.2 \mathrm{~mm}$ the mean of the whole investigated cohort. $C D L$ cochlear duct length

and calculating the AID. In comparison, our study focused on the anatomy with the analysis of differences in gender and age. Due to the large data set, our study benefits from an equal share of gender and sides, as well as a broad range of age. A possible downside, we see in the presented cohort, is the relatively small share of younger children, which lacks to than our study with analyzing inter- and intrarater reliability 
A

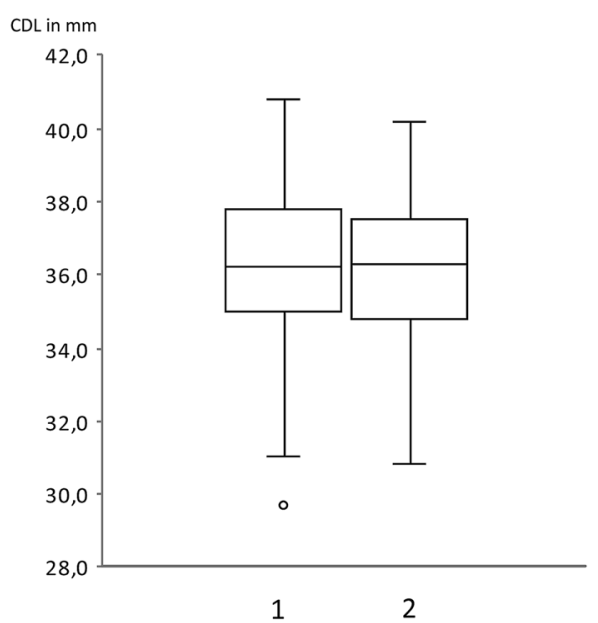

C

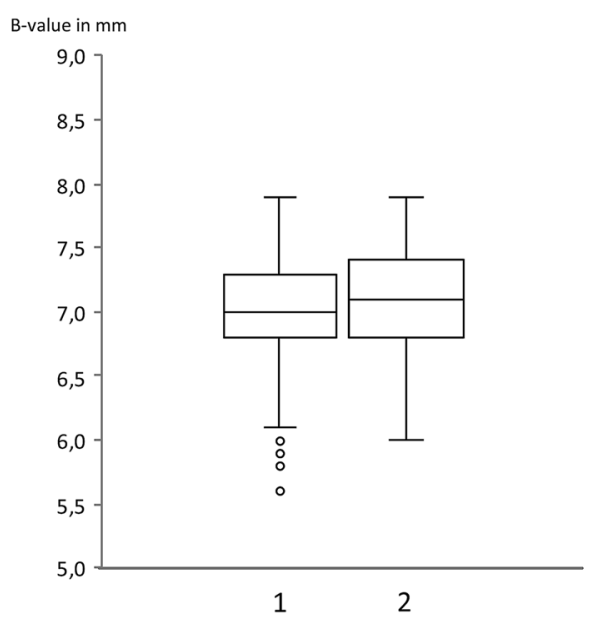

E

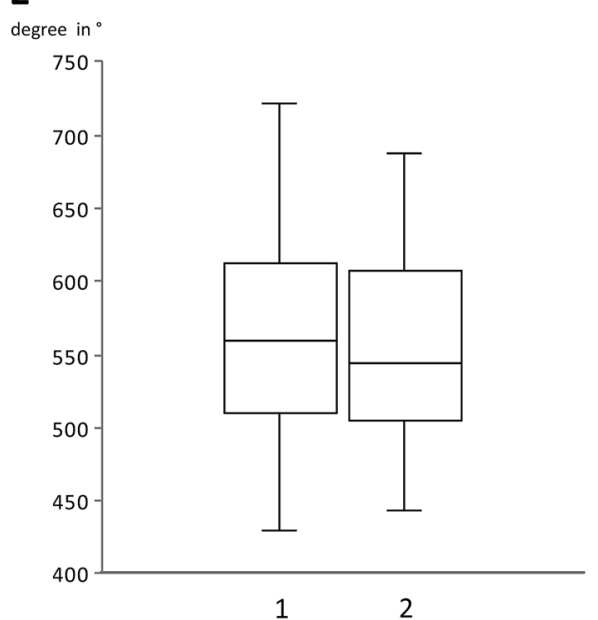

B

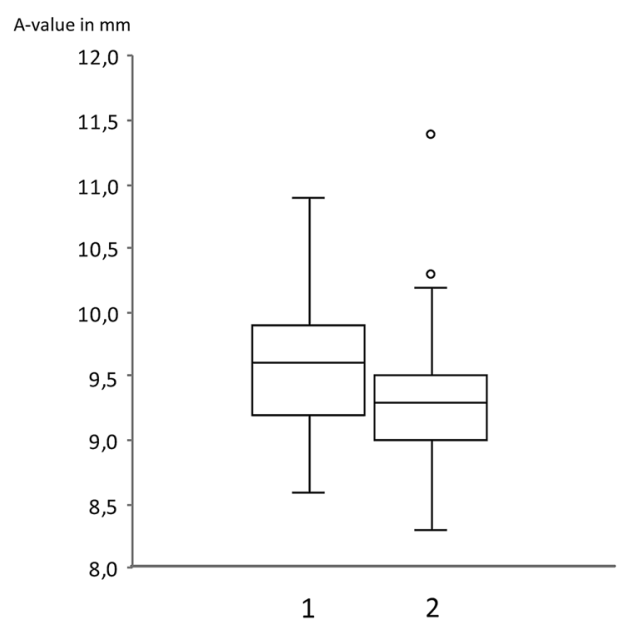

D

height in $\mathrm{mm}$

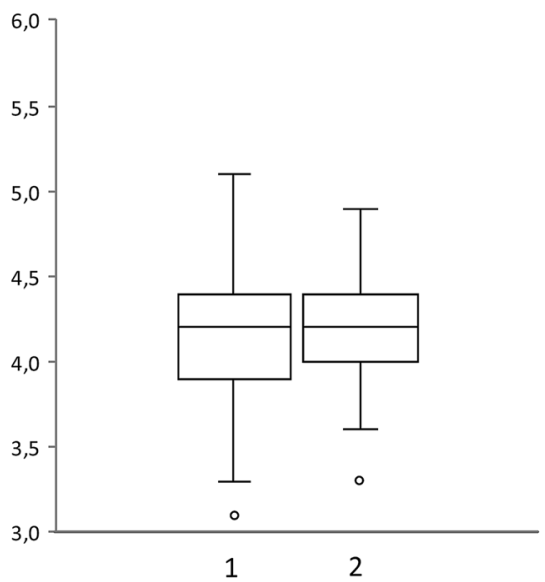

$\mathbf{F}$

cochlear coverage

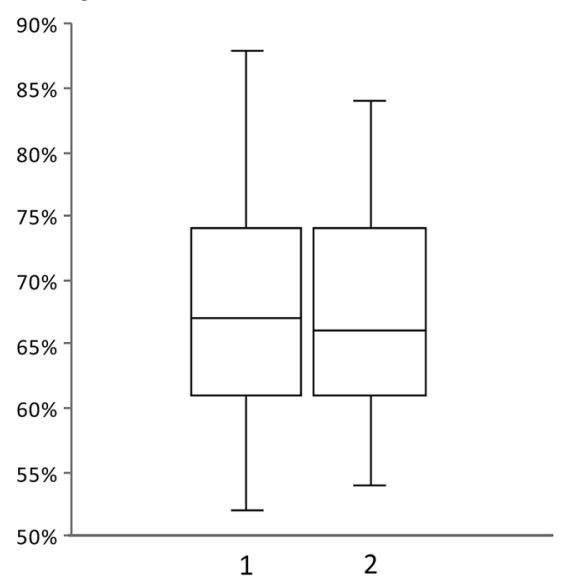

the OTOPLAN software was also performed in our study by calculating the excellent interrater reliability. The second study of Canfarotta et al. investigated the variability 
4Fig. 5 Interrater variability. Interrater reliability between the two blinded investigators. A Comparison of CDL ( $p$ value $=0.887$ ) between investigator 1 (left; $36.2 \pm 2.1 \mathrm{~mm}$ ) and investigator 2 (right; $36.2 \pm 1.8 \mathrm{~mm}$ ). The empty circles indicate outliners. B Comparison of A value ( $p$ value $=0.454)$ between investigator 1 (left; $9.5 \pm 0.5 \mathrm{~mm}$ ) and investigator 2 (right; $9.3 \pm 0.5 \mathrm{~mm}$ ). The empty circles indicate outliners. C Comparison of B value ( $p$ value $=0.412$ ) between investigator 1 (left; $7.0 \pm 0.5 \mathrm{~mm}$ ) and investigator 2 (right; $7.1 \pm 0.4 \mathrm{~mm}$ ). The empty circles indicate outliners. D Comparison of height of the cochlea ( $p$ value $=0.764$ ) between investigator 1 (left; $4.2 \pm 0.4 \mathrm{~mm}$ ) and investigator 2 (right; $4.2 \pm 0.3 \mathrm{~mm}$ ). The empty circles indicate outliners. E Comparison of AID ( $p$ value $=0.519)$ between investigator 1 (left; $561.3 \pm 63.6^{\circ}$ ) and investigator 2 (right; $\left.557.4 \pm 65.5^{\circ}\right)$. The empty circles indicate outliners. F Comparison of cochlear coverage ( $p$ value $=0.627$ ) between investigator 1 (left; $67.8 \pm 8.0 \%$ ) and investigator 2 (right; $67.9 \pm 8.0 \%$ ). The empty circles indicate outliners. $A I D$ angular insertion depth; $C D L$ cochlear duct length

in frequency-to-place mismatch in 111 recipients listening with CI and electric-acoustic stimulation (EAS) measuring the respective AID with the OTOPLAN software with lesser focus on anatomic variations [24]. Other studies analyzing the CDL regarding age or sex had smaller cohorts and lacked of an analysis of the interrater reliability [26, 27].

When comparing the presented values of CDL to studies using different techniques (Table 2), predominantly similar values are observed. Comparing the CDL with studies using the direct technique, a method where the CDL is measured directly on histologic slices, similar values to our study are found. In the largest cohort of 50 individuals applying the direct technique, Ulehlova and collaborators found a similar mean to our study of $34.2 \mathrm{~mm}$ with a similar range of $28.0-40.1 \mathrm{~mm}$ [4]. Other studies with smaller numbers ( $n=5$ to 35 ) observed lower means of CDL (33.13-34.0 mm) [28-31]. The comparison to studies generating the CDL with the $3 \mathrm{D}$-reconstruction method showed similar mean values and ranges [14, 32-35] in very large cohorts up to 436 individuals [34], as well. A predecessor technique to the method used with the OTOPLAN software is the technique of the spiral coefficient, introduced by Alexiades and collaborators [17]. Studies using this technique calculated similar values [15, 36-38]. Looking at studies using the OTOPLAN software, mean of CDL was lower (32.4-34.0 mm; Table 2) Comparing the AID of the study of Canfarotta and collaborators [19], slightly lower values were observed in our cohort with regard to the AID (525.4 ${ }^{\circ}$ versus $578^{\circ}$ ) for FLEX28 patients, and similar values for FLEXSOFT patients $\left(615.4^{\circ}\right.$ versus $\left.619^{\circ}\right)$. The application of the indirect technique, where a stack of histologic slices is used to reconstruct a two-dimensional model of the cochlea showed a broader variation in the mean CDL (range of mean: $28.4-42.0 \mathrm{~mm}$ ) [3, 39-43], which is accompanied by a known method error effect depending on the cutting angle of the histologic slices [33].
Concerning the observed significant difference of CDL in male and female patients in the present study, other studies also found longer cochleae in male individuals [27, 44, 45]. Contributing to the difference might be correlation to a larger height in the individual or a larger head diameter, which has not been investigated so far.

Looking at CDL and AID values generated by the present investigated tablet-based software OTOPLAN are comparable to studies with the named different techniques. In addition, the re-test variability was shown to be very low in both our study and Canfarotta et al. [19]. With a straightforward applicability of this tablet-based software, individualized CI implantation with precise personalized preoperative planning is feasible. With the results of our study, the known variance of the cochlea is once again demonstrated. Even if the morphology seems normal at first glance in the computed tomography, pitfalls might occur intraoperatively, like incomplete insertion in patients with shorter cochlea with kinking or tipfoldover of the electrode, or damage of the lamina spiralis. Interestingly, two cochleae were measured shorter than $32.0 \mathrm{~mm}$, meaning that in the remaining 106 patients the insertion of an electrode of $31.0 \mathrm{~mm}$ length, would have been feasible. Moreover, with regard to further implications and improvements of CI, the morphology, CDL and AID play an essential role. Referring to the data of the present study and Canfarotta et al. [19], in none of the FLEXSOFT ${ }^{\mathrm{TM}}$ patients the preferred AID of $720^{\circ}$, which would equal to two turns of the cochlea, was reached. This opens the discussion, if CI patients would benefit from longer electrodes covering a broader range of frequencies inside the cochlea. As the group around Canfarotta reported, patients with $\mathrm{CI}$ alone and longer electrodes seem to have a lower degree of frequency-to-place mismatch than patients with residual hearing and electric acoustic stimulation [24]. In addition, they found a better long-term speech recognition in patients with a $31.5 \mathrm{~mm}$ electrode, than those with a $24 \mathrm{~mm}$ array [46]. At the same time, the same research group observed a greater likelihood of preservation of the lower frequencies in patients with longer CDL (up to $36.5 \mathrm{~mm}$ ) with the same electrode $(31.5 \mathrm{~mm})$ [47]. Another study group observed a beneficial influence of deep insertion with regard to thresholds up to $65 \mathrm{~dB}$ at $0.5 \mathrm{kHz}$ [48]. Regarding musical sound quality discrimination, cochlea implant users with a $31.5 \mathrm{~mm}$ electrode had due to the greater apical stimulation an improved musical low-frequency perception in comparison to those with a $24.0 \mathrm{~mm}$ electrode [49]. Whereas, another study group observed no audiological benefit between groups of different electrode lengths (active lengths: $15.0 \mathrm{~mm}$ versus $19.1 \mathrm{~mm}$ versus $23.1 \mathrm{~mm}$ ) in single sided deafness patients [50].

Since we know of a certain variation of the CDL in the presented cohort of almost $10 \mathrm{~mm}$, the debate for longer electrodes versus an actual and verifiable audiological 
Table 2 Variation of cochlear duct length with regard to the different measuring techniques ${ }^{\mathrm{a}}$

\begin{tabular}{|c|c|c|c|c|c|c|c|}
\hline Author & Year & $n$ & Modality & Slice thickness & $\begin{array}{l}\text { Mean of CDL } \\
(\mathrm{SD}) \text { in } \mathrm{mm}\end{array}$ & Range of values in mm & $\begin{array}{l}\text { Calculated } \\
\text { difference } \\
\text { in } \%\end{array}$ \\
\hline \multicolumn{8}{|l|}{ Direct technique } \\
\hline Retzius [3] & 1884 & 5 & Histology & $\mathrm{n} / \mathrm{a}$ & $33.5(0.8)$ & $32.0-34.0$ & 6.3 \\
\hline Bredberg [28] & 1968 & 35 & Histology & $\mathrm{n} / \mathrm{a}$ & $31.5(2.3)$ & $30.3-37.6$ & 24.1 \\
\hline Úlehlová et al. [4] & 1987 & 50 & Histology & $\mathrm{n} / \mathrm{a}$ & $34.2(2.9)$ & $28.0-40.1$ & 43.2 \\
\hline Wright et al. [31] & 1987 & 14 & Histology & $\mathrm{n} / \mathrm{a}$ & $32.9(2.6)$ & $28.8-36.6$ & 27.1 \\
\hline Sridhar et al. [29] & 2006 & 7 & Histology & $\mathrm{n} / \mathrm{a}$ & $33.3(2.4)$ & $30.5-36.9$ & 20.1 \\
\hline Stakhovskaya et al. [30] & 2007 & 9 & Histology & $\mathrm{n} / \mathrm{a}$ & $33.1(2.1)$ & $30.5-36.9$ & 20.1 \\
\hline \multicolumn{8}{|l|}{ Indirect technique } \\
\hline Hardy [3] & 1938 & 68 & Histology & $\mathrm{n} / \mathrm{a}$ & $31.5(2.3)$ & $25.6-35.5$ & 38.7 \\
\hline Walby et al. [41] & 1985 & 20 & Histology & $\mathrm{n} / \mathrm{a}$ & $32.6(2.1)$ & $30.1-36.6$ & 21.6 \\
\hline Pollak et al. [40] & 1987 & 9 & Histology & $\mathrm{n} / \mathrm{a}$ & $28.4(3.4)$ & $24.0-33.5$ & 39.6 \\
\hline Erixon et al. [39] & 2009 & 58 & Plastic casts & $\mathrm{n} / \mathrm{a}$ & $42.0(2.0)$ & $38.6-45.6$ & 18.1 \\
\hline Lee et al. [42] & 2010 & 27 & Histology & $\mathrm{n} / \mathrm{a}$ & $30.8(2.6)$ & $25.5-35.1$ & 37.6 \\
\hline Erixon and Rask-Andersen [43] & 2013 & 51 & Plastic casts & $\mathrm{n} / \mathrm{a}$ & $41.2(1.9)$ & $37.6-44.9$ & 16.3 \\
\hline \multicolumn{8}{|l|}{$3 \mathrm{D}$ reconstruction } \\
\hline Takagi and Sando [14] & 1989 & 1 & Histology & $\mathrm{n} / \mathrm{a}$ & $36.4(\mathrm{n} / \mathrm{a})$ & $\mathrm{n} / \mathrm{a}$ & $\mathrm{n} / \mathrm{a}$ \\
\hline Sato et al. [32] & 1991 & 18 & Histology & $\mathrm{n} / \mathrm{a}$ & $34.7(2.9)$ & $29.7-38.9$ & 31.0 \\
\hline \multirow[t]{2}{*}{ Kawano et al. [33] } & 1996 & 8 & Histology & $\mathrm{n} / \mathrm{a}$ & $35.6(1.4)$ & $34.2-37.9$ & 10.8 \\
\hline & & 8 & Histology & $\mathrm{n} / \mathrm{a}$ & $40.8(2.0)$ & $37.9-43.8$ & 15.6 \\
\hline Würfel et al. [34] & 2014 & 218 & In vivo $\mathrm{CBCT}$ & $0.3 \mathrm{~mm}$ voxel & $37.9(2.0)$ & $30.8-43.2$ & 40.3 \\
\hline Meng et al. [35] & 2016 & 310 & In vivo $\mathrm{CT}$ & $0.7 \mathrm{~mm}$ & $35.8(2.0)$ & $30.7-42.2$ & 37.5 \\
\hline \multicolumn{8}{|l|}{ Spiral coefficients } \\
\hline Ketten et al. [15] & 1998 & 20 & In vivo $\mathrm{CT}$ & $1.0 \mathrm{~mm}$ & $33.0(2.3)$ & $29.1-37.5$ & 28.9 \\
\hline Skinner et al. [36] & 2002 & 26 & In vivo $\mathrm{CT}$ & $1.0 \mathrm{~mm}$ & $34.6(1.2)$ & $32.9-36.6$ & 11.2 \\
\hline Alanazi and Alzhrani [47] & 2018 & 401 & In vivo $\mathrm{CT}$ & $<1.0 \mathrm{~mm}$ & $31.9(\mathrm{n} / \mathrm{g})$ & $20.3-37.7$ & 85.7 \\
\hline Grover et al. [38] & 2018 & 124 & In vivo $\mathrm{CT}$ & $<1.0 \mathrm{~mm}$ & $29.8(\mathrm{n} / \mathrm{g})$ & $28.0-34.3$ & 22.5 \\
\hline \multicolumn{8}{|l|}{ Tablet-based software } \\
\hline Canfarotta et al. [19] & 2019 & 20 & In vivo $\mathrm{CT}$ & $\mathrm{n} / \mathrm{g}$ & n/g, only AID & n/g, only AID & $\mathrm{n} / \mathrm{a}$ \\
\hline Canfarotta et al. [24] & 2020 & 111 & In vivo $\mathrm{CT}$ & $\mathrm{n} / \mathrm{g}$ & $34.0(1.9)$ & $29.4-39.5$ & 34.4 \\
\hline Lovato et al. [26] & 2020 & 5 & In vivo $\mathrm{CT}$ & $\mathrm{n} / \mathrm{g}$ & $32.4(\mathrm{n} / \mathrm{g})$ & $30.7-33.3$ & 8.0 \\
\hline Khurayzi et al. [27] & 2020 & 88 & In vivo $\mathrm{CT}$ & $\mathrm{n} / \mathrm{g}$ & $32.9(1.8)$ & $28.1-37.8$ & 27.4 \\
\hline Present study & 2021 & 108 & In vivo $\mathrm{CT}$ & $<0.7 \mathrm{~mm}$ & $36.2(1.8)$ & & $32.2 \mathrm{tab}$ \\
\hline
\end{tabular}

${ }^{\text {a }}$ Modified according to Koch RW, et al. [11]

$A I D$ angular insertion depth; $C D L$ cochlear duct length; $n / a$ not applicable; $n / g$ not given; $S D$ standard deviation

benefit in everyday life remains open. Nevertheless, hearing outcome with a cochlear implant is influenced by many other factors, like uni- versus bilateral implantation, psychological state, motivation, socioeconomic status, profession, environment of the patient, etiology of hearing loss, hearing rehabilitation, age and time of implantation that there might not be an answer to the grade of contribution the electrode length has to the hearing result [51-54]. With an international multicenter CI-registry all-encompassing investigations could be generated to potentially answer this question.

\section{Conclusion}

Analysis with the tablet-based software OTOPLAN showed a broad range of CDL with a variation over $30 \%$ and significant differences in sex, but none in age or side. This broad range in CDL should be considered preoperatively for issues like avoidance of complications (incomplete insertion, kinking or tipfoldover of the electrode), attempt of atraumatic insertion, individual necessities (hearing preservation, cochlear malformation), and tonotopic matching of electrical stimulation site Further studies with correlation of CDL, hearing results, and tonotopic 
matching are required for different patient groups. Interestingly, the AID was smaller than Stenvers view head X-ray would have suggested, which again leaves room for the debate about longer electrodes versus a significant audiological benefit for patients in their daily life.

Supplementary Information The online version contains supplementary material available at https://doi.org/10.1007/s00405-021-06889-0.

Acknowledgements The authors are thankful for the advisory support of Stefan Brill.

Author contributions JLS conceptualized the study, collected and analyzed data, and wrote the paper; DP collected and analyzed data, and provided critical revision; MC and JMH provided critical revision; JES collected and analyzed data, and provided critical revision; JM conceptualized the study and provided critical revision. All authors discussed the results and implications and commented on the manuscript at all stages.

Funding Open Access funding enabled and organized by Projekt DEAL. The tablets with the software OTOPLAN version 2.0 were provided by the company MED-EL, GmbH, Innsbruck, Austria. Otherwise, the authors received no financial support for the research, authorship, and/or publication of this article.

Data availability Original data is available on demand.

Code availability Statistical analysis was performed with the software Real Statistics Resource Pack software (Release 6.8; www.real-stati stics.com) and Microsoft ${ }^{\circledR}$ Excel $^{\circledR}$ 16.0.12730.20144. The respective codes are available on demand.

\section{Declarations}

Conflict of interest Jennifer L. Spiegel, Daniel Polterauer, John-Martin Hempel, and Joachim Müller received travel expenses to a conference in Austria in September 2019 from MED-EL, GmbH, Innsbruck, Austria.

Ethical approval Study protocol was performed according to ethical guidelines of the 2002 Declaration of Helsinki, and carried out after approval by the Institutional Review Board and Ethics Committee of the Ludwig-Maximilians-Universität München, Munich, Germany (Ethikkommission der LMU München) (reference number 19-562).

Open Access This article is licensed under a Creative Commons Attribution 4.0 International License, which permits use, sharing, adaptation, distribution and reproduction in any medium or format, as long as you give appropriate credit to the original author(s) and the source, provide a link to the Creative Commons licence, and indicate if changes were made. The images or other third party material in this article are included in the article's Creative Commons licence, unless indicated otherwise in a credit line to the material. If material is not included in the article's Creative Commons licence and your intended use is not permitted by statutory regulation or exceeds the permitted use, you will need to obtain permission directly from the copyright holder. To view a copy of this licence, visit http://creativecommons.org/licenses/by/4.0/.

\section{References}

1. Sennaroglu L, Sarac S, Ergin T (2006) Surgical results of cochlear implantation in malformed cochlea. Otol Neurotol 27(5):615-623

2. Avci E, Nauwelaers T, Lenarz T, Hamacher V, Kral A (2014) Variations in microanatomy of the human cochlea. J Comp Neurol 522(14):3245-3261. https://doi.org/10.1002/cne.23594

3. Hardy M (1938) The length of the organ of corti in man. Am J Anat 62:291-311. https://doi.org/10.1002/aja.1000620204

4. Úlehlová L, Voldřich L, Janisch R (1987) Correlative study of sensory cell density and cochlear length in humans. Hear Res 28(2-3):149-151. https://doi.org/10.1016/0378-5955(87)90045-1

5. Bruce I, Todt I (2018) Hearing preservation cochlear implant surgery. Adv Otorhinolaryngol 81:66-73. https://doi.org/10.1159/ 000485544

6. Nordfalk K, Rasmussen K, Hopp E, Bunne M, Silvola J, Jablonski $\mathrm{G}$ (2016) Insertion depth in cochlear implantation and outcome in residual hearing and vestibular function. Ear Hear 37(2):e129_ e137. https://doi.org/10.1097/AUD.0000000000000241

7. MED EL Electronics. Electrode arrays designed for atraumatic implantation providing superior hearing performance. https://s3. medel.com/pdf/21617.pdf. Accessed 8 Apr 2020

8. Advanced Bionics. https://www.advancedbionics.com/content/ advancedbionics/com/en/home/products/hi-focus-electrode-family.html. Accessed 8 Apr 2020

9. Gibson P, Boyd P (2016) Optimal electrode design: straight versus perimodiolar. Eur Ann Otorhinolaryngol Head Neck Dis 133(Suppl 1):S63-65. https://doi.org/10.1016/j.anorl.2016.04.014

10. Cochlear. http://www.cochlear.com/wps/wcm/connect/us/home/ treatment-options-for-hearing-loss/cochlear-implants. Accessed 8 Apr 2020

11. Koch R, Ladak H, Elfarnawany M, Agrawal S (2017) Measuring cochlear duct length-a historical analysis of methods and results. J Otolaryngol Head Neck Surg 46:19. https://doi.org/10. 1186/s40463-017-0194-2

12. Guild S (1921) A graphic reconstruction method for the study of the organ of corti. Anat Rec 22:140-157. https://doi.org/10.1002/ ar. 1090220205

13. Schuknecht H (1953) Techniques for study of cochlear function and pathology in experimental animals: development of the anatomical frequency scale for the Cat. Arch Otolaryngol Head Neck Surg 58(4):377-397. https://doi.org/10.1001/archotol.1953.00710 040399001

14. Takagi A, Sando I (1989) Computer-aided three-dimensional reconstruction: a method of measuring temporal bone structures including the length of the cochlea. Ann Otol Rhinol Laryngol 98(7 Pt 1):515-522

15. Ketten D, Skinner M, Wang G, Vannier M, Gates G, Neely J (1998) In vivo measures of cochlear length and insertion depth of nucleus cochlear implant electrode arrays. Ann Oto Rhinol Laryngol 175:1-16

16. Escudé B, James C, Deguine O, Cochard N, Eter E, Fraysse B (2006) The size of the cochlea and predictions of insertion depth angles for cochlear implant electrodes. Audiol Neurootol Suppl $1: 27-33$

17. Alexiades G, Dhanasingh A, Jolly C (2015) Method to estimate the complete and two-turn cochlear duct length. Otol Neurotol 36(5):904-907

18. CAScination AG. https://www.cascination.com/products/otoplan. Accessed 8 Apr 2020

19. Canfarotta M, Dillon M, Buss E, Pillsbury H, Brown K, O’Connell B (2019) Validating a new tablet-based tool in the determination of cochlear implant angular insertion depth. Otol Neurotol 
40(8):1006-1010. https://doi.org/10.1097/MAO.0000000000 002296

20. World Medical Association (2000) World Medical Association Declaration of Helsinki: ethical principles for medical research involving human subjects. JAMA 284(23):3043-3045

21. Schurzig D, Timm M, Batsoulis C, Salcher R, Sieber D, Jolly C, Lenarz T, Zoka-Assadi M (2018) A novel method for clincial cochlear duct length estimation toward patient-specific cochlear implant selection. OTO Open 2(4):2473974X18800238

22. Greenwood D (1990) A cochlear frequency-position function for severalspecies: 29 years later. J Acoust Soc Am 87:2596-2605

23. Zaiontz C (2020) Real statistics using excel. www.real-statistics. com. Accessed 24 Apr 2020

24. Canfarotta MW, Dillon MT, Buss E, Pillsbury HC, Brown KD, O'Connell BP (2020) Frequency-to-place mismatch: characterizing variability and the influence on speech perception outcomes in cochlear implant recipients. Ear Hear 41(5):1349-1361. https:// doi.org/10.1097/AUD.0000000000000864

25. Teissier N, Van Den Abbeele T, Sebag G, Elmaleh-Berges M (2010) Computed tomography measurements of the normal and the pathologic cochlea in children. Pediatr Radiol 40(3):275-283. https://doi.org/10.1007/s00247-009-1423-2

26. Lovato A, Marioni G, Gamberini L, Bonora C, Genovese E, de Filippis C (2020) OTOPLAN in cochlear implantation for faradvanced otosclerosis. Otol Neurotol. https://doi.org/10.1097/ MAO.0000000000002722

27. Khurayzi T, Almuhawas F, Sanosi A (2020) Direct measurement of cochlear parameters for automatic calculation of the cochlear duct length. Ann Saudi Med 40(3):212-218. https://doi.org/10. 5144/0256-4947.2020.218

28. Bredberg G (1968) Cellular pattern and nerve supply of the human organ of corti. Acta Otolaryngol Suppl 236:1-138

29. Sridhar D, Stakhovskaya O, Leake P (2006) A frequency-position functionfor the human cochlear spiral ganglion. Audiol Neurotol 11(Suppl 1):16-20

30. Stakhovskaya O, Sridhar D, Bonham B, Leake P (2007) Frequency map for the human cochlear spiral ganglion: implications for cochlear implants. J Assoc Res Otolaryngol 8(2):220-233

31. Wright A, Davis A, Bredberg G, Ulehlova L, Spencer H (1987) Hair cell distributions in the normal human cochlea. Acta Otolaryngol Suppl 444:1-48

32. Sato H, Sando I, Takahashi H (1991) Sexual dimorphism and development of the human cochlea. Computer 3-D measurement. Acta Otolaryngol 111(6):1037-1040

33. Kawano A, Seldon H, Clark G (1996) Computer-aided threedimensional reconstruction in human cochlear maps: measurement of the lengths of organ of corti, outer wall, inner wall, and Rosenthal's canal. Ann Otol Rhinol Laryngol 105(9):701-709. https://doi.org/10.1177/000348949610500906

34. Würfel W, Lanfermann H, Lenarz T, Majdani O (2014) Cochlear length determination using cone beam computed tomography in a clinical setting. Hear Res 316:65-72

35. Meng J, Li S, Zhang F, Li Q, Qin Z (2016) Cochlear size and shape variability and implications in cochlear implantation surgery. Otol Neurotol 37(9):1307-1313. https://doi.org/10.1097/ MAO.0000000000001189

36. Skinner M, Ketten D, Holden L, Harding G, Smith P, Gates G, Neely J, Kletzker G, Brunsden B, Blocker B (2002) CT-derived estimation of cochlear morphology and electrode array position in relation to word recognition in Nucleus-22 recipients. J Assoc Res Otolaryngol 3(3):332-350

37. Alanazi A, Alzhrani F (2018) Comparison of cochlear duct length between the Saudi and non-Saudi populations. Ann Saudi Med 38(2):125-129. https://doi.org/10.5144/0256-4947.2018.125

38. Grover M, Sharma S, Singh S, Kataria T, Lakhawat R, Sharma M (2018) Measuring cochlear duct length in Asian population: worth giving a thought! Eur Arch Oto-Rhino-Laryngol 275(3):725-728. https://doi.org/10.1007/s00405-018-4868-9

39. Erixon E, Högstorp H, Wadin K, Rask-Andersen H (2009) Variational anatomy of the human cochlea: implications for cochlea implantation. Otol Neurotol 30(1):14-22. https://doi.org/10.1097/ MAO.0b013e31818a08e8

40. Pollak A, Felix H, Schrott A (1987) Methodological aspects of quantitative study of spiral ganglion cells. Acta Otolaryngol 436:37-42

41. Walby A (1985) Scala tympani measurement. Ann Otol Rhinol Laryngol 94(4 Pt 1):393-397

42. Lee J, Nadol JJ, Eddington D (2010) Depth of electrode insertion and postoperative performance in humans with cochlear implants: a histopathologic study. Audiol Neurootol 15(5):323-331. https:// doi.org/10.1159/000289571

43. Erixon E, Rask-Andersen H (2013) How to predict cochlear length before cochlear implantation surgery. Acta Otolaryngol 133:1258-1265. https://doi.org/10.3109/00016489.2013.831475

44. Doubi A, Almuhawas F, Alzhrani F, Doubi M, Aljutaili H, Hagr A (2019) The Effect of cochlear coverage on auditory and speech performance in cochlear implant patients. Otol Neurotol 40(5):602-607. https://doi.org/10.1097/MAO.0000000000002192

45. Thong J, Low D, Tham A, Liew C, Tan T, Yuen H (2017) Cochlear duct length-one size fits all? Am J Otolaryngol 38(2):218221. https://doi.org/10.1016/j.amjoto.2017.01.015

46. Canfarotta MW, Dillon MT, Buchman CA, Buss E, O'Connell BP, Rooth MA, King ER, Pillsbury HC, Adunka OF, Brown KD (2021) Long-term influence of electrode array length on speech recognition in cochlear implant users. Laryngoscope 131(4):892897. https://doi.org/10.1002/lary.28949

47. Hollis ES, Canfarotta MW, Dillon MT, Rooth MA, Bucker AL, Dillon SA, Young A, Quinones K, Pillsbury HC, Dedmon MM, O'Connell BP, Brown KD (2021) Initial hearing preservation is correlated with cochlear duct length in fully-inserted long flexible lateral wall arrays. Otol Neurotol. https://doi.org/10.1097/MAO. 0000000000003181

48. Helbig S, Adel Y, Leinung M, Stover T, Baumann U, Weissgerber $\mathrm{T}$ (2018) Hearing preservation outcomes after cochlear implantation depending on the angle of insertion: indication for electric or electric-acoustic stimulation. Otol Neurotol 39(7):834-841. https://doi.org/10.1097/MAO.0000000000001862

49. Roy AT, Penninger RT, Pearl MS, Wuerfel W, Jiradejvong P, Carver C, Buechner A, Limb CJ (2016) Deeper cochlear implant electrode insertion angle improves detection of musical sound quality deterioration related to bass frequency removal. Otol Neurotol 37(2):146-151. https://doi.org/10.1097/MAO.0000000000 000932

50. Speck I, Ketterer MC, Arndt S, Aschendorff A, Jakob TF, Hassepass F (2021) Comparison of speech recognition and localization ability in single-sided deaf patients implanted with different cochlear implant electrode array designs. Otol Neurotol 42(1):e22-e32. https://doi.org/10.1097/MAO.0000000000002864

51. Blamey P, Artieres F, Baskent D, Bergeron F, Beynon A, Burke E, Dillier N, Dowell R, Fraysse B, Gallego S, Govaerts PJ, Green K, Huber AM, Kleine-Punte A, Maat B, Marx M, Mawman D, Mosnier I, O'Connor AF, O'Leary S, Rousset A, Schauwers K, Skarzynski H, Skarzynski PH, Sterkers O, Terranti A, Truy E, Van de Heyning P, Venail F, Vincent C, Lazard DS (2013) Factors affecting auditory performance of postlinguistically deaf adults using cochlear implants: an update with 2251 patients. Audiol Neurootol 18(1):36-47. https://doi.org/10.1159/000343189

52. Lazard DS, Vincent C, Venail F, Van de Heyning P, Truy E, Sterkers O, Skarzynski PH, Skarzynski H, Schauwers K, O'Leary S, Mawman D, Maat B, Kleine-Punte A, Huber AM, Green K, Govaerts PJ, Fraysse B, Dowell R, Dillier N, Burke E, Beynon A, Bergeron F, Baskent D, Artieres F, Blamey PJ (2012) Pre-, 
per- and postoperative factors affecting performance of postlinguistically deaf adults using cochlear implants: a new conceptual model over time. PLoS ONE. https://doi.org/10.1371/journal. pone.0048739

53. Tyler RS, Moore BC, Kuk FK (1989) Performance of some of the better cochlear-implant patients. J Speech Hear Res 32(4):887911. https://doi.org/10.1044/jshr.3204.887

54. Geier L, Barker M, Fisher L, Opie J (1999) The effect of long-term deafness on speech recognition in postlingually deafened adult
CLARION cochlear implant users. Ann Otol Rhinol Laryngol Suppl 177:80-83. https://doi.org/10.1177/00034894991080s416

Publisher's Note Springer Nature remains neutral with regard to jurisdictional claims in published maps and institutional affiliations. 